\title{
Community-acquired bacteraemia in COVID-19 in comparison to influenza A and influenza B: a retrospective cohort study
}

Julinha M. Thelen ${ }^{1,2^{*}}$, A. G. ( Noud) Buenen ${ }^{3}$, Marjan van Apeldoorn ${ }^{4}$, Heiman F. Wertheim, Mirjam H. A. Hermans ${ }^{1}$ and Peter C. Wever ${ }^{1}$

\begin{abstract}
Background: During the coronavirus disease 2019 (COVID-19) pandemic in the Netherlands it was noticed that very few blood cultures from COVID-19 patients turned positive with clinically relevant bacteria. This was particularly evident in comparison to the number of positive blood cultures during previous seasonal epidemics of influenza. This observation raised questions about the occurrence and causative microorganisms of bacteraemia in COVID-19 patients, especially in the perspective of the widely reported overuse of antibiotics and the rising rate of antibiotic resistance.
\end{abstract}

Methods: We conducted a retrospective cohort study on blood culture results in influenza A, influenza B and COVID-19 patients presenting to two hospitals in the Netherlands. Our main outcome consisted of the percentage of positive blood cultures. The percentage of clinically relevant blood cultures, isolated bacteria and 30-day all-cause mortality served as our secondary outcomes.

Results: A total of 1331 viral episodes were analysed in 1324 patients. There was no statistically significant difference $(p=0.47)$ in overall occurrence of blood culture positivity in COVID-19 patients $(9.0,95 \% \mathrm{Cl} 6.8-11.1)$ in comparison to influenza A $(11.4,95 \% \mathrm{Cl} 7.9-14.8)$ and influenza B patients $(10.4,95 \% \mathrm{Cl} 7.1-13.7$,$) . After correcting$ for the high rate of contamination, the occurrence of clinically relevant bacteraemia in COVID-19 patients amounted to $1.0 \%(95 \% \mathrm{Cl} 0.3-1.8)$, which was statistically significantly lower $(p=0.04)$ compared to influenza A patients (4.0,95\% Cl 1.9-6.1) and influenza B patients (3.0, 95\% Cl 1.2-4.9). The most frequently identified bacterial isolates in COVID-19 patients were Escherichia coli $(n=2)$ and Streptococcus pneumoniae $(n=2)$. The overall 30-day all-cause mortality for COVID-19 patients was $28.3 \%$ (95\% CI 24.9-31.7), which was statistically significantly higher $(\mathrm{p}=<.001)$ when compared to patients with influenza A $(7.1,95 \% \mathrm{Cl} 4.3-9.9)$ and patients with influenza B (6.4, 95\% Cl 3.8-9.1).

Conclusions: We report a very low occurrence of community-acquired bacteraemia amongst COVID-19 patients in comparison to influenza patients. These results reinforce current clinical guidelines on antibiotic management in COVID-19, which only advise utilization of antibiotics when a bacterial co-infection is suspected.

\footnotetext{
* Correspondence: julinha@live.nl

'Department of Medical Microbiology and Infection Control, Jeroen Bosch

Hospital, 's-Hertogenbosch, the Netherlands

${ }^{2}$ Radboud University Nijmegen, Nijmegen, the Netherlands

Full list of author information is available at the end of the article
}

\section{$\triangle B M C$}

(c) The Author(s). 2021 Open Access This article is licensed under a Creative Commons Attribution 4.0 International License, which permits use, sharing, adaptation, distribution and reproduction in any medium or format, as long as you give appropriate credit to the original author(s) and the source, provide a link to the Creative Commons licence, and indicate if changes were made. The images or other third party material in this article are included in the article's Creative Commons licence, unless indicated otherwise in a credit line to the material. If material is not included in the article's Creative Commons licence and your intended use is not permitted by statutory regulation or exceeds the permitted use, you will need to obtain permission directly from the copyright holder. To view a copy of this licence, visit http://creativecommons.org/licenses/by/4.0/. The Creative Commons Public Domain Dedication waiver (http://creativecommons.org/publicdomain/zero/1.0/) applies to the data made available in this article, unless otherwise stated in a credit line to the data. 


\section{Introduction}

In December 2019, the Wuhan Municipal Health Commission in China reported a few cases of pneumonia with an unknown aetiology. In these cases, the novel severe acute respiratory syndrome coronavirus 2 (SARSCoV-2), was discovered [1, 2]. On February 27, 2020, the first case of coronavirus disease 2019 (COVID-19) was reported in the Netherlands [3]. After this first case, the SARS-CoV-2 virus spread rapidly in the south of the Netherlands. The southern region emerged as the Dutch epicentre of the first wave of COVID-19, putting a large strain on the microbiology laboratories in this area. $\mathrm{Nu}$ merous analyses of SARS-CoV-2 tests, blood cultures and respiratory samples were performed. It was observed that during this period very few blood cultures were positive as a result of relevant bacteraemia, especially in comparison to blood cultures collected during influenza seasons. This raised questions about the occurrence of bacteraemia and bacterial co-infections in COVID-19 patients.

Bacterial co-infections are frequently identified in influenza infections and are an important cause of morbidity and mortality [4, 5]. It is estimated that $11-35 \%$ of all patients with an influenza infection acquire a bacterial co-infection [6]. The most frequently isolated pathogens are Streptococcus pneumoniae, Staphylococcus aureus and Haemophilus influenzae [7]. Although the use of empiric antibiotics is only recommended when a bacterial co-infection is suspected, it is difficult for physicians to differentiate between a viral infection and bacterial co-infection [8, 9]. This contributes to a widely recognized overuse of antibiotics in patients with viral infections $[6,10,11]$. For COVID-19, little is known about the occurrence of bacterial co-infections and the causative pathogens. One small observational study in the Netherlands showed an overall co-infection rate of $16 \%$ in COVID-19 patients [12]. Gaining more knowledge on this subject is important, particularly when deciding on the appropriate antibiotic regimen. During the first wave of the COVID-19 pandemic, many patients received empiric antibiotics prior to and during their admission to the hospital [13]. Numbers range from $31 \%$ in the Netherlands to $95 \%$ in Asia [3, 14]. Cephalosporins and broad-spectrum penicillins were most frequently prescribed in the Netherlands [13]. Unnecessary use of antibiotics has many disadvantages, especially in the view of a rising rate of antibiotic resistance [15].

Studying the occurrence, causative microorganisms and outcome of bacteraemia in COVID-19 patients in comparison to influenza $\mathrm{A}$ and $\mathrm{B}$ patients will increase the knowledge about bacterial co-infections in COVID19 and possibly refine the current guidelines on antibiotic management.

\section{Methods}

\section{Study design and population}

We performed a retrospective cohort study of patients with an influenza A, influenza B or a COVID-19 diagnosis and analysed blood culture outcomes. Patients were enrolled from two different hospitals in the Netherlands, the Jeroen Bosch Hospital in 's-Hertogenbosch and Bernhoven Hospital in Uden. Patients were divided into three cohorts according to their infection status: (1) patients with an influenza A diagnosis in the influenza season 2015/2016 or 2016/2017, (2) patients with an influenza B diagnosis in influenza season 2017/2018 and (3) patients with a COVID-19 diagnosis between 28 February 2020 and 2 June 2020.

Patients were included when an influenza or a COVID-19 infection was confirmed by reverse transcription polymerase chain reaction (RT-PCR) on RNA from oropharyngeal swabs (in case of influenza) or oronasopharyngeal swabs (in case of COVID-19). Blood cultures were collected within a time interval of $48 \mathrm{~h}$ before and after the RT-PCR test.

Included into our analysis were patients attending the emergency department, patients diagnosed with influenza or COVID-19 at outpatients clinics who were subsequently hospitalized and patients who developed fever or flu-like symptoms during early hospitalization for other medical reasons. Patients who were discharged from the emergency department were analysed as well.

The following information was recorded and collected in an anonymous database: demographic data, viral diagnosis, blood culture results, names of isolated bacteria, likelihood of contamination, the hospital ward where the blood culture was collected, blood culture collection date and time and outcome of hospitalization expressed as 30-day all-cause mortality. Predominantly the data were extracted from the laboratory information system (MOLIS). Only the outcome of hospitalization was manually collected from the patient's medical record. Bacteria were categorized as likely contaminants if they were affiliated to groups that represent commensal skin microbiota and were defined in the patient's medical record as a contaminant by the Department of Medical Microbiology [16].

The percentage of positive blood cultures served as our primary outcome. Secondary outcomes were the percentage of relevant blood cultures, causative microorganisms and 30-day all-cause mortality.

This study was performed in line with the principles of the Declaration of Helsinki. The board of directors of both the Jeroen Bosch Hospital and Bernhoven Hospital approved this study. Additional ethical approval was granted by the Medical Ethical Review Committee Brabant (METC Brabant). Due to the collected data being held anonymously, informed consent was waived by the 
scientific review boards of both the Jeroen Bosch Hospital and Bernhoven Hospital for this study. Patients who had stated an objection to utilization of their medical data for scientific research in their electronic medical record were excluded from this study.

\section{Data analysis}

Categorical variables are displayed as frequencies and percentages. Means and standard deviations were used to report continuous variables. The categorical variables were compared using the chi-square test or the Fisher's exact test. The continuous variables were compared using a one-way analysis of variance (ANOVA). A $p$ value $<0.05$ was considered statistically significant. All analyses were performed with SPSS version 26.0 for Windows.

\section{Results}

\section{Study characteristics}

We examined 1635 patients who had blood cultures analysed and a diagnosis of either influenza A, influenza B or COVID-19. Some patients appeared multiple times in the list extracted from the laboratory information system due to numerous positive tests for one virus obtained during hospitalization. These patients were included only once, at the time of presentation to the hospital. Other patients were excluded due to blood cultures not collected within $48 \mathrm{~h}$ of viral testing. In the end, a total of 1324 patients were included. Seven patients were included twice due to being hospitalized with two different viral infections during various viral seasons. Therefore, the total number of viral episodes amounted to 1331 . Among these, there were 325 influenza A infections, 328 influenza $\mathrm{B}$ infections and 678 COVID-19 infections. Blood cultures were collected at the emergency department in $88.2 \%$ of all viral episodes. There were no differences between the cohorts regarding median age. The frequency of males was higher in the influenza A cohort (58.2\%) and in the COVID-19 cohort (65.1\%). Detailed demographics are listed in Table 1.

\section{Bacteraemia and clinical outcomes}

There was no statistically significant difference $(\mathrm{p}=0.47$, Table 2) in the occurrence of blood culture positivity in influenza A patients (11.4, 95\% CI 7.9-14.8), influenza B patients (10.4, 95\% CI 7.1-13.7) and COVID-19 patients (9.0, 95\% CI 6.8-11.1). After correcting for likely contaminants, the occurrence of relevant bacteraemia in COVID-19 patients declined to $1.0 \%$ (95\% CI $0.3-1.8$ ), which was statistically significantly lower $(p=0.04)$ than in influenza A patients $(4.0,95 \%$ CI 1.9-6.1) and influenza B patients (3.0, 95\% CI 1.2-4.9). COVID-19 patients with relevant bacteraemia were significantly older ( $p=0.03$, Table 3$)$ in comparison to patients without bacteraemia. No significant difference in gender was found in COVID-19 patients with relevant bacteraemia and patients without bacteraemia. The overall 30-day all-cause mortality rate was significantly higher $(\mathrm{p}=<.001$, Table 4 in patients with COVID-19 (28.3, 95\% CI 24.9-31.7) compared to patients with influenza A (7.1, 95\% CI 4.3-9.9) and patients with influenza B $(6.4,95 \%$ CI 3.8-9.1). When examining the 30-day mortality in patients with positive blood cultures, a significantly higher mortality $(p=0.02$, Table 4$)$ was found in patients in the influenza A cohort (18.9, 95\% CI 6.3-31.5) and patients in the COVID-19 cohort (26.2, 95\% CI 15.2-37.3) compared to patients in the influenza B cohort $(2.9,95 \%$ CI - 2.7-8.4). There was no statistically significant difference in 30-day all-cause mortality between the different cohorts among patients with relevant bacteraemia.

Table 1 Demographics of patients with influenza A, influenza B or COVID-19

\begin{tabular}{|c|c|c|c|}
\hline & $\begin{array}{l}\text { Influenza A } \\
(n=325)\end{array}$ & $\begin{array}{l}\text { Influenza B } \\
(n=328)\end{array}$ & $\begin{array}{l}\text { COVID-19 } \\
(n=678)\end{array}$ \\
\hline \multicolumn{4}{|l|}{ Gender, n (\%) } \\
\hline Male & $189(58.2)$ & $162(49.4)$ & $443(65.1)$ \\
\hline Age (years), median (interquartile range) & $71(59-81)$ & $74(64-83)$ & $70(58-78)$ \\
\hline \multicolumn{4}{|l|}{ Age categorized (years), n (\%) } \\
\hline$<40$ & $29(9.0)$ & $20(6.1)$ & $19(2.8)$ \\
\hline $40-60$ & $56(17.2)$ & $42(12.8)$ & $179(26.3)$ \\
\hline$>60$ & $240(73.8)$ & $266(81.1)$ & $483(70.9)$ \\
\hline \multicolumn{4}{|l|}{ Presentation, n (\%) } \\
\hline Emergency Department & $292(89.8)$ & $272(82.9)$ & $613(90.4)$ \\
\hline Outpatient clinic & $1(0.3)$ & $1(0.3)$ & $4(0.6)$ \\
\hline Nursing ward & $31(9.5)$ & $52(15.9)$ & $55(8.1)$ \\
\hline Intensive care & $1(0.3)$ & $3(0.9)$ & $6(0.9)$ \\
\hline
\end{tabular}


Table 2 Proportion of positive blood cultures in patients with influenza A, influenza B or COVID-19

\begin{tabular}{|c|c|c|c|c|c|c|c|}
\hline & \multicolumn{2}{|c|}{$\begin{array}{l}\text { Influenza A } \\
(n=325)\end{array}$} & \multicolumn{2}{|c|}{$\begin{array}{l}\text { Influenza B } \\
(n=328)\end{array}$} & \multicolumn{2}{|c|}{$\begin{array}{l}\text { COVID-19 } \\
(n=678)\end{array}$} & \multirow[b]{2}{*}{ p value ${ }^{* *}$} \\
\hline & $\%(n)$ & $95 \% \mathrm{Cl}$ & $\%(n)$ & $95 \% \mathrm{Cl}$ & $\%(n)$ & $95 \% \mathrm{Cl}$ & \\
\hline Positive blood cultures & $11.4(37)$ & $7.9-14.8$ & $10.4(34)$ & $7.1-13.7$ & $9.0(61)$ & $6.8-11.1$ & 0.47 \\
\hline Relevant positive blood cultures* & 4.0 (13) & $1.9-6.1$ & $3.0(10)$ & $1.2-4.9$ & $1.0(7)$ & $0.3-1.8$ & 0.04 \\
\hline
\end{tabular}

* Corrected for contamination

** Pearson's chi-squared test

$95 \% \mathrm{Cl}=95 \%$ confidence interval

\section{Causative microorganisms of bacteraemia}

A total of 135 bacteria were isolated from 132 patients with positive blood cultures in the different cohorts. Of the 64 bacterial isolates in COVID-19 patients, 57 (89.1\%) consisted of coagulase-negative staphylococci and other bacterial species that can be regarded as contaminants. This percentage of contamination was higher than in influenza A (64.9\%) and influenza B patients (70.6\%).

Escherichia coli and S. pneumoniae were the most common pathogens identified in patients with COVID19 , each accounting for $28.6 \%(n=2)$ of bacteria causing a relevant bacteraemia. Other pathogens causing relevant bacteraemia in COVID-19 patients were: S. aureus, Klebsiella pneumoniae and Pseudomonas aeruginosa (all $n=1)$. S. pneumoniae was the most common cause of relevant bacteraemia among influenza A patients, causing $76.9 \%(n=10)$ of all bloodstream infections in this cohort. The most frequently isolated bacteria in influenza B patients were $S$. pneumoniae and $S$. aureus, each accounting for $40.0 \%(n=4)$ of all isolated bacteria. No bacteria seemed to be overrepresented in COVID-19 patients. The bacterial pathogens identified are further detailed in Tables 5 and 6 .

\section{Discussion}

Our study showed that only $1.0 \%$ of COVID-19 patients presenting at a general hospital experienced a clinically relevant bacteraemia, compared to $4.0 \%$ in influenza A patients and $3.0 \%$ in influenza B patients. E. coli and $S$. pneumoniae were most frequently isolated from positive blood cultures in COVID-19 patients. The same pathogens were also common in influenza $\mathrm{A}$ and $\mathrm{B}$ patients. We reported a 30 -day all-cause mortality of $28.3 \%$ in COVID-19 patients, which was statistically significantly higher than the 30-day all-cause mortality of 7.1 and $6.4 \%$ found in respectively influenza $\mathrm{A}$ and $\mathrm{B}$ patients.

Our results are consistent with findings in a recent study of Sepulveda et al. [17]. They performed a large multicentre cohort analysis on patients with COVID-19 in New York. The authors reported a true bacteraemia rate of $1.6 \%$. The most common causative microorganisms of bacteraemia in their study population were $E$. coli, S. aureus, K. pneumoniae and Enterobacter cloacae complex. A study of Hughes et al. also described similar findings [18]. The authors reported an occurrence of bacteraemia of $3.2 \%$. This percentage consisted of both hospital- and community-acquired infections. We only reported on community-acquired infections, which may explain the difference. Their most frequently isolated community-acquired pathogens were Enterobacterales, Streptococcus spp., S. aureus and Enterococcus spp. A recent study of Goyal et al. noted a bacteraemia rate of $5.6 \%$ in COVID-19 patients [19]. This is significantly higher than the $1.0 \%$ that our study reported. Like Hughes et al., these authors examined both hospitalacquired and community-acquired infections, which may explain the higher rate of bacteraemia.

We reported a blood culture contamination rate of 89.1\% amongst COVID-19 patients. This percentage is fairly consistent with other studies $[17,18]$. This high percentage may be explained by the high workload and the recruitment of more inexperienced health care workers during the pandemic.

We found a 30-day all-cause mortality of $28.3 \%$ in our COVID-19 cohort. This number is relatively high compared to recent reports from Europe that describe 30day all-cause mortality rates ranging from 19.7 to $21.5 \%$ $[20,21]$. This disparity may be attributed to the higher risk of severe disease in our study population. During

Table 3 Demographics of COVID-19 patients with relevant bacteraemia and patients without bacteraemia

\begin{tabular}{llll}
\hline & $\begin{array}{l}\text { Relevant bacteraemic patients } \\
(\boldsymbol{n}=\mathbf{7})\end{array}$ & $\begin{array}{l}\text { Non-bacteraemic patients } \\
(\boldsymbol{n}=671)\end{array}$ & $\mathbf{p}$ value \\
\hline Gender, $\mathrm{n}(\%)$ & & $438(65.3)$ & $0.72^{*}$ \\
$\quad$ Male & $4(57.1)$ & $70(58-78)$ & $0.03^{* *}$ \\
\hline Age (years), median (interquartile range) & $83(70-85)$ & & \\
\hline
\end{tabular}

* Pearson's chi-squared test

** One-way ANOVA 
Table 4 The 30-day all-cause mortality rate in patients with influenza A, influenza B or COVID-19 stratified by blood culture results

\begin{tabular}{|c|c|c|c|c|c|c|c|}
\hline \multirow[b]{2}{*}{ Mortality rate } & \multicolumn{2}{|c|}{ Influenza A } & \multicolumn{2}{|c|}{ Influenza B } & \multicolumn{2}{|l|}{ COVID-19 } & \multirow[b]{2}{*}{$p$ value } \\
\hline & $\%(n)$ & $95 \% \mathrm{Cl}$ & $\%(n)$ & $95 \% \mathrm{Cl}$ & $\%(n)$ & $95 \% \mathrm{Cl}$ & \\
\hline Overall & $7.1(23)$ & $4.3-9.9$ & $6.4(21)$ & $3.8-9.1$ & $28.3(192)$ & $24.9-31.7$ & $<.001^{* *}$ \\
\hline With positive blood culture & $18.9(7)$ & $6.3-31.5$ & $2.9(1)$ & $-2.7-8.4$ & $26.2(16)$ & $15.2-37.3$ & $0.02^{* *}$ \\
\hline With relevant positive blood culture* & 30.8 (4) & $5.7-55.9$ & $10.0(1)$ & $-8.6-28.6$ & 42.9 (3) & $6.2-79.5$ & $0.28^{* * *}$ \\
\hline
\end{tabular}

* Corrected for contamination

** Pearson's chi-squared test

*** Fisher's exact test

$95 \% \mathrm{Cl}=95 \%$ confidence interval

the first wave of COVID-19, family doctors in our region were asked to refer only severe cases to the overloaded hospitals. Furthermore, we only included patients with COVID-19 and analysed blood cultures. The required collection of blood cultures suggests these patients experienced severe febrile illness which indicates more severe disease.

Our findings on bacteraemia in influenza patients are consistent with prior studies [22, 23]. We reported a slightly lower rate of bacteraemia in influenza B patients in comparison to influenza A patients. This is in agreement with the assertion that influenza B often leads to milder disease and less co-infections when compared to influenza A [24, 25]. The 30-day allcause mortality rate amongst influenza patients in our cohort was comparable to mortality rates mentioned in other literature $[20,26]$.

Our findings support current guidelines on antibiotic management that do not recommend the use of empiric antibiotics in patients with COVID-19 unless there is a clear suspicion of an accompanying bacterial infection

Table 5 Bacteria isolated from positive blood cultures stratified by infection status

\begin{tabular}{llll}
\hline & \multicolumn{3}{l}{ Positive blood cultures } \\
\cline { 2 - 4 } Pathogen, $\mathbf{n}(\%)$ & $\begin{array}{l}\text { Influenza A } \\
(\boldsymbol{n}=\mathbf{3 7})\end{array}$ & $\begin{array}{l}\text { Influenza B } \\
(\boldsymbol{n}=\mathbf{3 4})\end{array}$ & $\begin{array}{l}\text { COVID-19 } \\
(\boldsymbol{n}=\mathbf{6 1})\end{array}$ \\
\hline Escherichia coli & $1(2.7)$ & $1(2.9)$ & $2(3.1)$ \\
Klebsiella pneumoniae & $1(2.7)$ & - & $1(1.6)$ \\
Pseudomonas aeruginosa & - & - & $1(1.6)$ \\
Micrococcus luteus & $1(2.7)$ & - & - \\
Streptococcus pneumoniae & $10(27.0)$ & $4(11.8)$ & $2(3.1)$ \\
Other Streptococcus species* & $1(2.7)$ & $1(2.9)$ & $1(1.6)$ \\
Staphylococcus aureus & $1(2.7)$ & $4(11.8)$ & $1(1.6)$ \\
CNS & $20(54.1)$ & $23(67.7)$ & $55(85.8)$ \\
Bacillus simplex & $1(2.7)$ & - & - \\
Brevibacterium casei & - & $1(2.9)$ & - \\
Corynebacterium species & $1(2.7)$ & - & $1(1.6)$ \\
Total & $37(100)$ & $34(100)$ & $64(100)^{* *}$ \\
\hline
\end{tabular}

CNS = Coagulase-negative staphylococci

* Streptococcus salivarius, Streptococcus pyogenes, Streptococcus vestibularis

** Multiple bacteria were isolated from some of the blood cultures
[8]. However, differentiating between viral disease and a bacterial co-infection can be a challenge for physicians. Procalcitonin levels may be of assistance in determining the likelihood of bacterial co-infection and a potential adverse outcome [27]. When a bacterial co-infection is suspected and empiric antibiotics are administered, we advise to regularly collect blood cultures and respiratory samples. The antibiotic therapy may then be deescalated or completely terminated based on the microbiological results. These recommendations will help in preventing overuse and the occurrence of potential sideeffects from antibiotics.

A major strength of our study is the inclusion of over 1300 patients from two different hospitals in the Netherlands. This large sample size increases the accuracy and reliability of our results. In addition, we reported on community-acquired infections. Most studies on bacterial co-infections in COVID-19 failed to report on the setting of their study and possibly investigated hospitalacquired infections as well, which negatively affects the interpretability of their results [17, 28-30]. Finally, we did not experience any missing data, which minimizes the potential risk of information bias.

Some limitations should be mentioned. We did not collect data on prior antibiotic use, which may have led to an underestimation of the actual occurrence of bacteraemia in COVID-19 and influenza patients. Although the sample size of this study was of a reasonably large magnitude, the actual number of patients experiencing relevant bacteraemia was quite low, subgroup analyses

Table 6 Bacteria isolated from positive blood cultures after correcting for contamination, stratified by infection status

\begin{tabular}{llll}
\hline Pathogen, $\mathbf{n}(\%)$ & \multicolumn{3}{l}{ Positive blood cultures } \\
\cline { 2 - 4 } & $\begin{array}{l}\text { Influenza A } \\
(\boldsymbol{n}=\mathbf{1 3})\end{array}$ & $\begin{array}{l}\text { Influenza B } \\
(\mathbf{n}=\mathbf{1 0})\end{array}$ & $\begin{array}{l}\text { COVID-19 } \\
(\boldsymbol{n}=\mathbf{7})\end{array}$ \\
\hline Escherichia coli & $1(7.7)$ & $1(10.0)$ & $2(28.6)$ \\
Klebsiella pneumoniae & $1(7.7)$ & - & $1(14.3)$ \\
Pseudomonas aeruginosa & - & - & $1(14.3)$ \\
Streptococcus pneumoniae & $10(76.9)$ & $4(40.0)$ & $2(28.6)$ \\
Streptococcus pyogenes & - & $1(10.0)$ & - \\
Staphylococcus aureus & $1(6.7)$ & $4(40.0)$ & $1(14.3)$ \\
\hline
\end{tabular}


of the 30-day all-cause mortality are therefore unreliable. In addition, we only reported on patients with bacteraemia and did not investigate other manifestations of bacterial co-infections. Thus, these results do not represent the entirety of bacterial co-infections in influenza and COVID-19 patients.

In conclusion, the proportion of clinically relevant community-acquired bacteraemia in COVID-19 patients was very low in comparison to influenza patients. These results justify the prudent use of empiric antibiotics in COVID-19 patients, when there is insufficient evidence of a bacterial co-infection.

\section{Acknowledgements}

We thank the Department of Medical Microbiology and Infection Control and the scientific research department in both the Jeroen Bosch Hospital and Bernhoven Hospital for providing access to the necessary operating systems and clinical data. We thank Suzanne Levels, application administrator, for her support with formulating and executing the search in the laboratory information system.

\section{Authors' contributions}

Thelen JM designed the proof outline, acquired and analysed the data and wrote the manuscript with support of Wever PC. Buenen AG, van Apeldoorn M, Wertheim HF and Hermans MHA discussed the results and reviewed the final manuscript. The author(s) read and approved the final manuscript.

\section{Funding}

We did not receive any endorsement or funding.

\section{Availability of data and materials}

The datasets used and analysed during the current study are available from the corresponding author on reasonable request.

\section{Ethics approval and consent to participate}

The scientific review boards of both the Jeroen Bosch Hospital and Bernhoven Hospital approved this study. Ethical approval was granted by the Medical Ethical Committee Brabant. Due to the collected data being held anonymously, informed consent was waived. This was in line with the regulations of the hospital boards of both the Jeroen Bosch Hospital and Bernhoven Hospital.

\section{Consent for publication}

Not applicable.

\section{Competing interests}

There is no conflict of interest to declare.

\section{Author details}

'Department of Medical Microbiology and Infection Control, Jeroen Bosch Hospital, 's-Hertogenbosch, the Netherlands. ${ }^{2}$ Radboud University Nijmegen, Nijmegen, the Netherlands. ${ }^{3}$ Department of Emergency Medicine, Bernhoven Hospital, Uden, the Netherlands. ${ }^{4}$ Department of Internal Medicine, Jeroen Bosch Hospital, 's-Hertogenbosch, the Netherlands. ${ }^{5}$ Department of Medical Microbiology, Radboud university medical center, Nijmegen, the Netherlands.

Received: 2 December 2020 Accepted: 5 February 2021

Published online: 22 February 2021

\section{References}

1. Li Q, Guan X, Wu P, et al. Early transmission dynamics in Wuhan, China, of novel coronavirus-infected pneumonia. N Engl J Med. 2020;382(13):1199207. https://doi.org/10.1056/NEJMoa2001316.

2. Lu H, Stratton CW, Tang YW. Outbreak of pneumonia of unknown etiology in Wuhan, China: the mystery and the miracle. J Med Virol. 2020 Apr;92(4): 401-2. https://doi.org/10.1002/jmv.25678.
3. Alderweireld CEA, Buiting AGM, Murk JLAN, Verweij JJ, Berrevoets MAH, van Kasteren MEE. COVID-19: patiënt nul in Nederland. Ned Tijdschr Geneeskd. 2020;164:D496 Only published online.

4. Chertow DS, Memoli MJ. Bacterial coinfection in influenza: a grand rounds review. JAMA. 2013;309(3):275-82. https://doi.org/10.1001/jama.2012.194139 PMID: 23321766.

5. Thompson WW, Shay DK, Weintraub E, et al. Mortality associated with influenza and respiratory syncytial virus in the United States. JAMA. 2003; 289(2):179-86. https://doi.org/10.1001/jama.289.2.179.

6. Klein EY, Monteforte B, Gupta A, et al. The frequency of influenza and bacterial coinfection: a systematic review and meta-analysis. Influenza Other Respir Viruses. 2016;10(5):394-403. https://doi.org/10.1111/irv.12398.

7. Morris DE, Cleary DW, Clarke SC. Secondary bacterial infections associated with influenza pandemics. Front Microbiol. 2017;8:1041. https://doi.org/10.33 89/fmicb.2017.01041

8. Getahun H, Smith I, Trivedi K, Paulin S, Balkhy HH. Tackling antimicrobial resistance in the COVID-19 pandemic. Bull World Health Orgn. 2020;98:442442A. https://doi.org/10.2471/BLT.20.268573.

9. Sieswerda E, de Boer MGJ, Bonten MMJ, Boersma WG, Jonkers RE, Aleva RM, Kullberg BJ, Schouten JA, van de Garde EMW, Verheij TJ, van der Eerden MM, Prins JM, Wiersinga WJ. Recommendations for antibacterial therapy in adults with COVID-19 - an evidence based guideline. Clin Microbiol Infect. 2020;S1198-743X(20):30594-2. https://doi.org/10.1016/j.cmi.2020.09.041 Epub ahead of print. PMID: 33010444; PMCID: PMC7527308.

10. Gonzales R, Bartlett JG, Besser RE, et al. Principles of appropriate antibiotic use for treatment of acute respiratory tract infections in adults: background, specific aims, and methods. Ann Intern Med. 2001;134(6):479-86. https://doi. org/10.7326/0003-4819-134-6-200103200-00013.

11. Metlay JP, Camargo CA Jr, MacKenzie T, et al. Cluster-randomized trial to improve antibiotic use for adults with acute respiratory infections treated in emergency departments. Ann Emerg Med. 2007;50(3):221-30. https://doi. org/10.1016/j.annemergmed.2007.03.022.

12. Buenen AG, Wever PC, Borst DP, Slieker KA. COVID-19 op de Spoedeisende hulp in Bernhoven. Ned Tijdschr Geneeskd. 2020;164: D500 Only published online.

13. Karami Z, Knoop BT, Dofferhoff ASM, Blaauw MJT, Janssen NA, van Apeldoorn M, Kerckhoffs APM, van de Maat JS, Hoogerwerf JJ, Ten Oever J. Few bacterial co-infections but frequent empiric antibiotic use in the early phase of hospitalized patients with COVID-19: results from a multicentre retrospective cohort study in The Netherlands. Infect Dis (Lond). 2020:1-9. https://doi.org/10.1080/23744235.2020.1839672 Epub ahead of print. PMID: 33103530.

14. Zhou F, Yu T, Du R, et al. Clinical course and risk factors for mortality of adult inpatients with COVID-19 in Wuhan, China: a retrospective cohort study. Lancet. 2020;395(10229):1054-62. https://doi.org/10.1016/ S0140-6736(20)30566-3.

15. Aslam B, Wang W, Arshad Ml, et al. Antibiotic resistance: a rundown of a global crisis. Infect Drug Resist. 2018;11:1645-58. https://doi.org/10.214 7/IDR.S173867.

16. Hall KK, Lyman JA. Updated review of blood culture contamination. Clin Microbiol Rev. 2006:19(4):788-802. https://doi.org/10.1128/CMR.00062-05.

17. Sepulveda J, Westblade LF, Whittier S, et al. Bacteremia and blood culture utilization during COVID-19 surge in New York City. J Clin Microbiol. 2020. https://doi.org/10.1128/JCM.00875-20.

18. Hughes S, Troise O, Donaldson H, Mughal N, Moore LSP. Bacterial and fungal coinfection among hospitalized patients with COVID-19: a retrospective cohort study in a UK secondary-care setting. Clin Microbiol Infect. 2020;S1198-743X(20)30369-4. doi:https://doi.org/10.101 6/j.cmi.2020.06.025

19. Goyal P, Choi JJ, Pinheiro LC, et al. Clinical characteristics of Covid-19 in New York City. N Engl J Med. 2020;382(24):2372-4. https://doi.org/10.1056/ NEJMc2010419.

20. Nersesjan V, Amiri M, Christensen HK, Benros ME, Kondziella D. 30-day mortality and morbidity in COVID-19 versus influenza: A population based study. medRxiv 2020.07.25.20162156; doi: https://doi.org/10.1101/2020.07.2 5.20162156 .

21. Giacomelli A, Ridolfo AL, Milazzo L, Oreni L, Bernacchia D, Siano M, Bonazzetti C, Covizzi A, Schiuma M, Passerini M, Piscaglia M, Coen M, Gubertini G, Rizzardini G, Cogliati C, Brambilla AM, Colombo R, Castelli A, Rech R, Riva A, Torre A, Meroni L, Rusconi S, Antinori S, Galli M. 30-day mortality in patients hospitalized with COVID-19 during the first wave of the 
Italian epidemic: A prospective cohort study. Pharmacol Res. 2020;158: 104931. https://doi.org/10.1016/j.phrs.2020.104931 Epub 2020 May 22. PMID: 32446978; PMCID: PMC7242199.

22. Cillóniz C, Ewig S, Menéndez R, et al. Bacterial co-infection with H1N1 infection in patients admitted with community acquired pneumonia. J Inf Secur. 2012;65(3):223-30. https://doi.org/10.1016/j.jinf.2012.04.009.

23. Teng F, Liu X, Guo SB, et al. Community-acquired bacterial co-infection predicts severity and mortality in influenza-associated pneumonia admitted patients. J Infect Chemother. 2019;25(2):129-36. https://doi.org/10.1016/j.jia c.2018.10.014

24. Aebi T, Weisser M, Bucher E, Hirsch HH, Marsch S, Siegemund M. Coinfection of Influenza B and Streptococci causing severe pneumonia and septic shock in healthy women. BMC Infect Dis. 2010;10:308. Published 2010 Oct 27. https://doi.org/10.1186/1471-2334-10-308.

25. Mancini DA, Alves RC, Mendonça RM, et al. Influenza virus and proteolytic bacteria co-infection in respiratory tract from individuals presenting respiratory manifestations. Rev Inst Med Trop Sao Paulo. 2008;50(1):41-6. https://doi.org/10.1590/s0036-46652008000100009.

26. von Baum H, Schweiger B, Welte T, Marre R, Suttorp N, Pletz MWR, Ewig S. How deadly is seasonal influenza-associated pneumonia? The German competence network for community-acquired pneumonia. Eur Respir J. 2011:37(5):1151-7. https://doi.org/10.1183/09031936.00037410.

27. Han J, Gatheral T, Williams C. Procalcitonin for patient stratification and identification of bacterial co-infection in COVID-19. Clin Med (Lond). 2020; 20(3):e47 doi:10.7861/clinmed. Let.20.3.3.

28. Chen $N$, Zhou M, Dong $X$, et al. Epidemiological and clinical characteristics of 99 cases of 2019 novel coronavirus pneumonia in Wuhan, China: a descriptive study. Lancet. 2020;395(10223):507-13. https://doi.org/10.1016/ S0140-6736(20)30211-7.

29. Rawson TM, Moore LSP, Zhu N, et al. Bacterial and fungal co-infection in individuals with coronavirus: A rapid review to support COVID-19 antimicrobial prescribing. Clin Infect Dis. 2020;ciaa530. https://doi.org/10.1 093/cid/ciaa530

30. Wang Z, Yang B, Li Q, Wen L, Zhang R. Clinical features of 69 cases with coronavirus disease 2019 in Wuhan, China. Clin Infect Dis. 2020 71(15):769-77. https://doi.org/10.1093/cid/ciaa272.

\section{Publisher's Note}

Springer Nature remains neutral with regard to jurisdictional claims in published maps and institutional affiliations.

Ready to submit your research? Choose BMC and benefit from:

- fast, convenient online submission

- thorough peer review by experienced researchers in your field

- rapid publication on acceptance

- support for research data, including large and complex data types

- gold Open Access which fosters wider collaboration and increased citations

- maximum visibility for your research: over $100 \mathrm{M}$ website views per year

At $\mathrm{BMC}$, research is always in progress.

Learn more biomedcentral.com/submissions 